\title{
Forensic and psychiatric aspects of joint suicide with carbon monoxide
}

\author{
Patrick Johannes Laberke • Horst Bock • \\ Volker Dittmann · Roland Hausmann
}

Accepted: 25 January 2011/Published online: 16 February 2011

(C) Springer Science+Business Media, LLC 2011

\begin{abstract}
A case of joint suicide of a young woman and man who became acquainted in a suicide web forum and used this platform to make an appointment to commit suicide together is described. During their investigation, police were able to reconstruct the events by analysing the computer of the deceased women which was also found with the bodies. An indoor charcoal burning unit was used to release carbon monoxide as the method of suicide.
\end{abstract}

Keywords Joint suicide - Schizophrenia - Internet · Carbon monoxide - Charcoal burning - Barbecue

\section{Introduction}

Accidental, suicidal and homicidal intoxications with carbon monoxide ( $\mathrm{CO}$ ) have a long history. Until the implementation of the catalytic converter, suicides in Europe were mainly caused by the inhalation of vehicle exhaust fumes [1, 2]. In the Far East intentional inhalation of $\mathrm{CO}$, predominantly produced by burning charcoal in closed spaces, has been a common method of suicide for decades [3-10]. Indoor usage of charcoal barbecues may lead to significant $\mathrm{CO}$ concentrations within hours [11]. In recent

P. J. Laberke $(\bowtie) \cdot$ V. Dittmann $\cdot$ R. Hausmann Institute of Legal Medicine, University of Basel, Pestalozzistr 22, 4056 Basel, Switzerland

e-mail: partick.laberke@bs.ch

H. Bock

District Court Memmingen, Hallhof 1+4, 87700 Memmingen, Germany years an increasing number of similar suicidal intoxications have been reported throughout Europe [2, 12-15].

The following report describes the joint suicide of a young woman suffering from schizophrenia and a man experiencing a personal crisis, which was conducted by inhalation of carbon monoxide. Their initial contact was established via the internet.

\section{Case report}

In spring 2010 the cleaning service of a holiday apartment discovered the corpses of a man and a woman, both regularly clothed and lying on the floor (Fig. 1). All doors and windows were locked from the inside. A patio barbecue with abundant ashes and dishes with the remains of grilled meat products were found beside the deceased. The crime scene investigation revealed cherry-red livor and no obvious signs of a struggle, so an accidental carbon monoxide intoxication was assumed.

During the following investigation, no connection between the two deceased could be drawn. There was no evidence that they had been involved in a relationship. Analysis of the woman's notebook computer, also found at the scene, followed. The first relevant website, visited in October 2009, led to the homepage of an organisation offering assisted suicide. An extensive article concerning 'suicide using charcoal' had been downloaded. Shortly after this the woman had joined a suicide forum. In her profile she assigned a mental illness as the reason for her two-year ongoing suicidal tendency and asked for someone to take the final step with her. For the following months several contacts to other members were documented. At the end of February she made initial contract with her final suicide partner. 


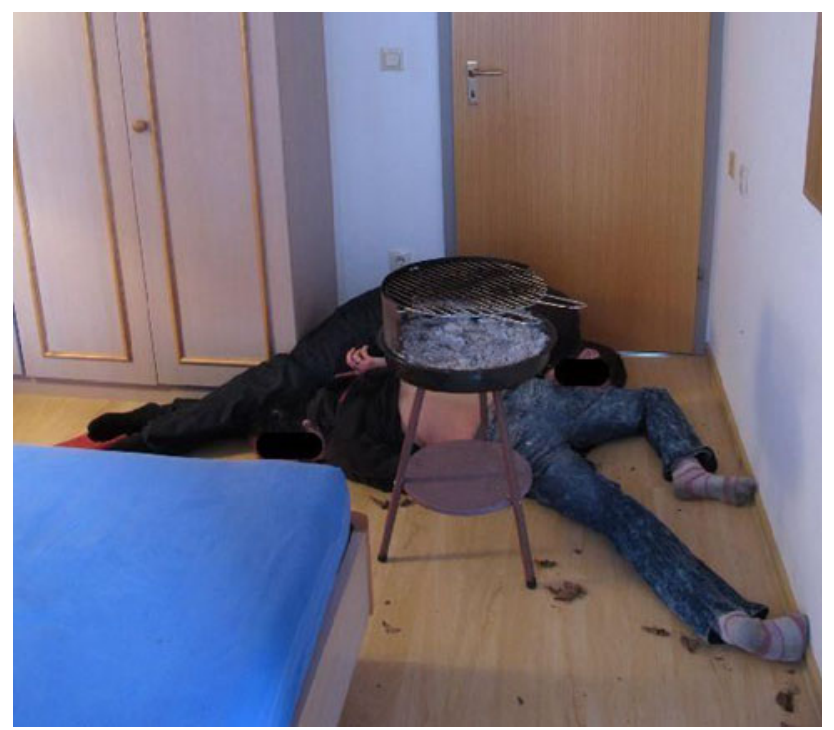

Fig. 1 Death scene showing the two bodies lying together

Further investigation into the medical record of the woman revealed pharmacologically treated schizophrenia and bulimia. Apart from difficulties with his marriage, no other problems could be determined in the man's history. No mental or physical issues were found in his internet profile. A loss of purpose in life was given as reason for his 1 year long suicidal ideation.

\section{Autopsies}

In both autopsies cherry-red livor mortis and blood were obvious. No signs of violence or other causes of death could be detected in the 23-year-old, healthy woman. The heart of the 30-year-old man showed mild hypertrophy, the liver mild lipomatosis. Relevant illnesses or injuries were not detected.

\section{Toxicology}

Standard chemical-toxicological testing was performed by immunoassay, gas chromatography-mass spectrometry (GC-MS) and high performance liquid chromatography (HPLC) and showed amphetamines and their derivates in the urine and blood of the femoral vein of both deceased. In the woman's blood a concentration of amphetamine of $32 \mathrm{ng} / \mathrm{ml}$ was detected. In the man's blood a concentration of $20 \mathrm{ng} / \mathrm{ml}$ was detected. Alcohol analysis was carried out enzymatically $(\mathrm{ADH})$ and with gas chromatography-electron capture detector (GC-ECD) and showed negative results in the woman. In the man's blood an alcohol concentration of $0.31 \mathrm{~g} / \mathrm{L}$ was found. CO detection in blood from the heart was performed by spectrophotometry. The $\mathrm{CO}$ concentration in the woman measured $65 \%$ and in the man $70 \%$.

\section{Discussion}

At first glance the cases appeared to be straightforward accidental $\mathrm{CO}$ intoxications in connection with the use of an indoor barbecue. Not until inconsistencies concerning the relations between the deceased emerged and further investigations were initiated, were the deaths revealed to be a joint suicide. Data from the computer of the woman showed that she had been gathering information about committing suicide and had become a member of a suicide internet forum months before. Two months before the incident she corresponded with her final suicide partner on this platform.

Suicidal ideation is a common phenomenon in the general population and suicide is one of the leading causes of death worldwide [16-18]. Media reporting of suicides is known to influence suicidal behavior, particularly the choice of method used [19]. Nowadays the internet plays an important role in suicide. In the last decade reports of cybersuicides and appointments for joint suicides have emerged [20, 21]. Detailed instructions can be found online, there are many platforms encouraging suicidal behavior and it is very easy to contact like-minded people to make appointments for a joint suicide. In the German-speaking region alone, there are approximately 30 suicide forums. Two studies examined the extent to which information on methods of committing suicide and pro-suicide websites could be found. Recupero [22] found pro-suicidal content in over $40 \%$ of websites dealing with suicide. Biddle and colleagues [23] found that half of the suicide sites provided some information on how to commit suicide and were encouraging, promoting or facilitating suicide. Additional risks on these sites are an easy access and hyperlinks or advertisements for online pharmacies selling medications used for committing suicide. Therefore depressed, suicidal or potentially suicidal persons who use the internet may be especially in danger [22].

In the review of the man's history no significant problems could be discovered except difficulties with his relationship. In the woman's medical history pharmacologically treated schizophrenia was described. Approximately $1 \%$ of the population develops schizophrenia during their lifetime. One of the main causes of mortality in schizophrenia is suicide with a prevalence of $4-5 \%$, which can be reduced by antipsychotic treatment [24-26]. Appropriate substances were prescribed for the woman, but could not be detected in the toxicological analysis. Other drugs, alcohol or illicit substances in significant concentrations were not found in either deceased. In the end the initial suspicion of lethal carbon monoxide intoxication could be validated as cause of death.

These cases highlight the importance of correlating forensic examinations with scene investigations. Without an analysis of the computer records of the deceased woman the true nature of these two deaths would not have been 
revealed, and while the manner of the deaths has no legal consequence it is pertinent to insurance law.

\section{Key points}

1. Suicide is one of the leading causes of death worldwide and is a significant cause of mortality in schizophrenia

2. The number of suicides by inhalation of carbon monoxide has been increasing over the last years in Europe

3. Nowadays, indoor charcoal burning is mainly used to produce carbon monoxide

4. The internet and suicide web forums are playing an increasingly important role in suicide

Conflict of interest The authors declare that they have no conflict of interest.

\section{References}

1. Hepp U, Ring M, Frei A, Rössler W, Schnyder U, Ajdacic-Gross V. Suicide trends diverge by method: Swiss suicide rates 1969-2005. Eur Psychiatry. 2010;25(3):129-35.

2. Wirth I, Schulz R, Schmeling A. Suicide means of a charcoal grill. Casuistic report with review of the literature. Arch Kriminol. 2008;211(5-6):129-37.

3. Akaishi S, Oshida S, Hiraiwa K, et al. Homicidal and camouflaged carbon monoxide poisoning in Japan. Z Rechtsmed. 1982;88:297-304.

4. Chang SS, Gunnell D, Wheeler BW, Yip P, Sterne JA. The evolution of the epidemic of charcoal-burning suicide in Taiwan: a spatial and temporal analysis. PloS Med. 2010;7(1):e1000212.

5. Huh GY, Jo GR, Kim KH, Ahn YW, Lee SY. Imitative suicide by burning charcoal in the southeastern region of Korea: the influence of mass media reporting. Leg Med (Tokyo). 2009;11(1): $563-4$.

6. Law CK, Yip PS, Caine ED. The contribution of charcoal burning to the rise and decline of suicides in Hong Kong from 1997-2007. Soc Psychiatry Psychiatr Epidemiol. 2010; epub ahead of print.

7. Lin JJ, Chang SS, Lu TH. The leading methods of suicide in Taiwan, 2002-2008. BMC Public Health. 2010;10:480.

8. Liu KY, Beautrais A, Caine E, et al. Charcoal burning suicides in Hong Kong and urban Taiwan: an illustration of the impact of a novel suicide method overall regional rates. J Epidemiol Community Health. 2007;61(3):248-53.

9. Pan YJ, Lee MB. Charcoal burning and maternal filicide-suicide trends in Taiwan: the impact of accessibility of lethal methods. J Formos Med Assoc. 2008;107(10):811-5.

10. Pan YJ, Liao SC, Lee MB. Suicide by charcoal burning in Taiwan, 1995-2006. J Affect Disord. 2010;120(1-3):254-7.

11. Kijewski H. Kohlenmonoxid. In: Madea B, Brinkman B (Hrsg.), editors. Handbuch gerichtliche Medizin 2. Berlin/Heidelberg: Springer; 2003. pp. 239-45.

12. Brooks-Lim EW, Sadler DW. Suicide by burning barbeque charcoal: three case reports. Med Sci Law. 2009;49(4):301-6.

13. Eckardt J, Seliger U, Keutel K, et al. Tödliche verlaufende Kohlenmonoxidintoxikationen. Rechtsmedizin. 2010. doi:10.1007/ s00194-010-0682-4.

14. Hartwig S, Tsokos M. Suicidal and accidental carbon monoxide poisonings due to charcoal fires in closed spaces. Arch Kriminol. 2008;222(1-2):1-13.

15. Lyness JR, Crane J. Carbon monoxide poisoning from disposable charcoal barbeques. Am J Forensic Med Pathol. 2010; epub ahead of print.

16. Borges G, Nock MK, Haro Abad JM, et al. Twelve-month prevalence of and risk factors for suicide attempts in the world health organization world mental health surveys. J Clin Psychiatry. 2010; epub ahead of print.

17. Lee JI, Lee MB, LIao SC, et al. Prevalence of suicidal ideation and associated risk factors in the general population. J Formos Med Assoc. 2010;109(2):138-47.

18. World Health Organization. Figures and facts about suicide. WHO, Geneva, 1999. http://www.who.int/mental_health/media/ en/382.pdf.

19. Hawton K, Williams K. Influences of the media on suicide. BMJ. 2002;325:1374-5.

20. Alao AO, Soderberg M, Pohl EL, Alao AL. Cybersuicide: review of the role of the internet on suicide. Cyberpsychol Behav. 2006;9(4):489-93.

21. Birbal R, Maharajh HD, Birbal R, et al. Cybersuicide and the adolescent population: challanges of the future? Int $\mathrm{J}$ Adolec Med Health. 2009;21(2):151-9.

22. Recupero PR, Harms SE, Noble JM. Googling suicide: surfing for suicide information on the internet. $\mathrm{J}$ Clin Psychiatry. 2008;69(6):878-88.

23. Biddle L, Dinovan J, Hawton K, Kapur N, Gunnell D. Suicide and the internet. BMJ. 2008;336(7648):800-2.

24. Bushe CJ, Taylor M, Haukka J. Mortality in schizophrenia: a measurable clinical endpoint. J Psychopharmacol. 2010; 24(4):17-25.

25. Carlborg A, Winnerbäck K, Jönsson EG, Jokinen J, Nordström P. Suicide in schizophrenia. Expert Rev Neurother. 2010;10(7): 1153-64.

26. Hor K, Taylor M. Suicide in schizophrenia: a systematic review of rates and risk factors. J Psychopharmacol. 2010;24(4):81-90. 